\title{
Potential patient benefit of a subcutaneous formulation of tocilizumab for the treatment of rheumatoid arthritis: a critical review
}

This article was published in the following Dove Press journal:

Patient Preference and Adherence

I August 2014

Number of times this article has been viewed

\author{
Emilio Besada \\ Bone and Joint Research Group, \\ Department of Clinical Medicine, \\ Faculty of Health Sciences, UiT \\ the Arctic University of Norway, \\ Tromsø, Norway
}

Correspondence: Emilio Besada Bone and Joint Research Group, Institute of Clinical Medicine, University of Tromsø, 9037 Tromsø, Norway

Tel +47 77627294

Fax +47 77627258

Email emilio.besada@uit.no
Abstract: Treatment of rheumatoid arthritis (RA) was revolutionized during the last decade with the development of new biologic disease-modifying anti-rheumatic drugs (DMARDs) enabling the targeting of immune cells and cytokines other than tumor necrosis factor (TNF). Subcutaneous formulations of the newer biologic DMARDs facilitate not only patients' emancipation from the hospital, but reduce both societal and medical costs. Intravenous tocilizumab (TCZ) in RA has an efficacy and safety profile similar to anti-TNF in both the short and long-term. However, TCZ can be administered in monotherapy without loss of efficacy when patients do not tolerate methotrexate or synthetic DMARDs. TCZ is consistently found superior to methotrexate and possibly superior to adalimumab in monotherapy in randomized controlled trials. Subcutaneous administration of TCZ is as effective and safe as its intravenous administration in RA patients during the first year of treatment. Similar to intravenous TCZ, patients' weight and possibly previous use of anti-TNF influence the efficacy of subcutaneous TCZ. Additionally, combination with synthetic DMARDs seems to expose RA patients to more adverse events independently of its administration route. Pharmacokinetics of different administration routes could potentially lead to differences in efficacy, adverse events, and auto-immunogenicity. The concentration of free TCZ before new TCZ dose (C trough) is higher in the subcutaneous route, while the maximal concentration of free TCZ is higher in the intravenous route. The subcutaneous dosages of TCZ $162 \mathrm{mg}$ every week, and every 2 weeks in RA patients with low body weight $(<60 \mathrm{~kg}$ ) work well. Nevertheless, dosage and intervals of subcutaneous TCZ administration could be adjusted during the course of treatment since $80 \%$ of non-Japanese RA patients with usually higher body weight achieved similar efficacy with the low TCZ dosage in combination with a synthetic DMARD. Patients want effective, easy-to-administer therapy with sustained prolonged efficacy without the need of polypharmacy and with minimal to no side effects. Subcutaneous TCZ in RA patients in monotherapy seems to live up to patients' expectations.

Keywords: tocilizumab, subcutaneous, rheumatoid arthritis, pharmacokinetic, safety, efficacy

\section{Introduction}

Rheumatoid arthritis (RA) is a chronic systemic inflammatory auto-immune disease responsible for articular and extra-articular affection. Clinical features of RA include symmetric polyarthritis of small joints and morning stiffness. ${ }^{1}$ More than a third of RA patients eventually experience work disability ${ }^{2}$ and life expectancy is shortened by 3-5 years due to disease and treatment-related adverse effects. ${ }^{3}$

Major advances in the management of RA are early diagnosis ${ }^{4}$ and prompt aggressive treatment aiming at remission. ${ }^{5}$ European League Against Rheumatism (EULAR) 
recommendations ${ }^{6}$ and treatment algorithms serving as pragmatic approaches in the management of $\mathrm{RA}^{1}$ have been published and have become standard-of-care.

Glucocorticoids, synthetic disease-modifying antirheumatic drugs (DMARD) and in the last 20 years biologic DMARD are used to treat RA. A combination of synthetic DMARD - especially methotrexate (MTX) - and biologic DMARD (anti-tumor necrosis factor (TNF), abatacept, rituximab, and tocilizumab [TCZ]) is recommended in patients responding inadequately to MTX after 3-6 months. ${ }^{6}$ Previous preference for a combination of antiTNF and MTX is no longer suggested in the last EULAR recommendations since abatacept and TCZ are as effective and safe as anti-TNF. ${ }^{6}$

Interleukin-6 (IL-6) is a pleiotropic cytokine involved in inflammation and infection responses, but also in the regulation of metabolic, regenerative, and neural processes. ${ }^{7}$ IL-6 targets cells with membrane bound IL-6 receptors (classic signaling), but also all other cells since IL-6 binds to the soluble form of IL-6 receptor which interacts with the signaling receptor protein gp130 (trans-signaling). ${ }^{7}$ Pro-inflammatory responses of Il-6 are rather mediated by trans-signaling. ${ }^{7}$ In RA patients, levels of IL-6 are increased in the synovial fluid and tissue and correlate with $\mathrm{C}$-reactive protein (CRP) and disease activity. ${ }^{8}$

TCZ is a recombinant humanized anti-IL-6 receptor monoclonal antibody approved in RA (intravenously at the dose of 4-8 $\mathrm{mg} / \mathrm{kg}$ every 4 weeks [q4w]) and in juvenile idiopathic arthritis (from $8-12 \mathrm{mg} / \mathrm{kg}$ every 2 weeks [q2w]) in Europe and the US. ${ }^{9}$ TCZ has also been used in Castleman disease and in non-RA systemic inflammatory rheumatic diseases such as adult-onset Still's disease, giant cell arteritis, Takayasu arteritis, polymyalgia rheumatica, relapsing polychondritis, systemic lupus erythematosus, and systemic sclerosis. ${ }^{9}$
Subcutaneous formulations of biologic DMARD other than anti-TNF, such as abatacept ${ }^{10}$ and TCZ in RA, have been developed in order to facilitate their use outside hospitals by permitting self-administration. The use of subcutaneous biologic agents other than anti-TNF could also be attractive in patients with non-RA systemic inflammatory rheumatic diseases.

A systematic search of the literature conducted prior to March 2014 with PubMed of the US National Library of Medicine and Google scholar using the key terms tocilizumab and subcutaneous identified two phase I/II and three phase III studies of subcutaneous TCZ in RA patients. ${ }^{11-16}$ The objective of the review is to present the available data concerning the pharmacokinetics, efficacy, and safety of subcutaneous TCZ in RA patients.

\section{Main differences between studies}

BREVACTA and SUMMACTA were global studies and comprised patients with RA from North and South America, Europe, and Asia (other than Japan), ${ }^{13-15}$ whereas MATSURI and MUSASHI only comprised Japanese patients (see Table 1). ${ }^{12,16}$

MATSURI was a phase I/II study that aimed to determine the appropriate dose of TCZ in Japanese RA patients, ${ }^{12}$ whereas the three other studies were phase III studies that aimed to establish the efficacy of subcutaneous TCZ formulation against placebo ${ }^{13,14}$ and against intravenous TCZ administration. ${ }^{15,16}$ The primary outcome of the two studies comparing subcutaneous and intravenous TCZ was to demonstrate the non-inferiority of subcutaneous TCZ when compared to intravenous TCZ with regard to efficacy. ${ }^{15,16}$ The non-inferiority margins used in the SUMMACTA and MUSASHI studies, $12 \%$ and $18 \%$ respectively, were defined empirically. ${ }^{15,16}$ The choice of the non-inferiority margin in the MUSASHI study was determined as a third of the difference of American College of Rheumatology (ACR)

Table I Characteristics of studies of subcutaneous tocilizumab in rheumatoid arthritis patients

\begin{tabular}{|c|c|c|c|c|c|c|c|c|}
\hline & Phase & Type of study & $\begin{array}{l}\text { Number } \\
\text { of patients }\end{array}$ & Treatment arms & DMARD & $\begin{array}{l}\text { Primary } \\
\text { endpoint }\end{array}$ & $\begin{array}{l}\text { Study } \\
\text { duration }\end{array}$ & Extension \\
\hline $\begin{array}{l}\text { MATSURI } \\
\text { (Japan) }^{12}\end{array}$ & $\begin{array}{l}\mathrm{I} / \mathrm{ll} \text { dose } \\
\text { escalation }\end{array}$ & Open trial & $8,12,12$ & $\begin{array}{l}81 \mathrm{mg} \text { q2w SC } \\
162 \mathrm{mg} \mathrm{q} 2 \mathrm{w} \text { SC } \\
162 \mathrm{mg} \text { qw SC }\end{array}$ & None & $\begin{array}{l}\text { Serum TCZ } \\
\text { concentration }\end{array}$ & $24 w$ & None \\
\hline $\begin{array}{l}\text { BREVACTA } \\
\text { (worldwide) }^{13,14}\end{array}$ & III db & $\mathrm{RCT}$ & 437 vs 219 & $\begin{array}{l}\text { TCZ I } 62 \mathrm{mg} \text { q2w SC vs } \\
\text { placebo }\end{array}$ & With & ACR20 & $24 w$ & $\begin{array}{l}\text { Open label } \\
\text { during } 72 \mathrm{w}\end{array}$ \\
\hline $\begin{array}{l}\text { SUMMACTA } \\
\text { (worldwide) }{ }^{15}\end{array}$ & III db, dd & $\begin{array}{l}\text { Non-inferiority } \\
\text { RCT }\end{array}$ & 558 vs 537 & $\begin{array}{l}\text { TCZ I62 mg qw SC vs } \\
\text { TCZ } 8 \mathrm{mg} / \mathrm{kg} \text { q4w IV }\end{array}$ & With & ACR20 & $24 w$ & $\begin{array}{l}\text { Open label } \\
\text { during } 72 \mathrm{w}\end{array}$ \\
\hline $\begin{array}{l}\text { MUSASHI } \\
\text { (Japan) }^{16}\end{array}$ & III db, dd & $\begin{array}{l}\text { Non-inferiority } \\
\text { RCT }\end{array}$ & 159 vs 156 & $\begin{array}{l}\text { TCZ } 162 \mathrm{mg} \mathrm{q} 2 \mathrm{w} \text { SC vs } \\
\text { TCZ } 8 \mathrm{mg} / \mathrm{kg} \mathrm{q} 4 \mathrm{w} \mathrm{IV}\end{array}$ & None & ACR20 & $24 w$ & NA \\
\hline
\end{tabular}

Abbreviations: ACR, American College of Rheumatology response rate 20; db, double-blind; dd, double dummy; DMARD, disease-modifying antirheumatic drugs; IV, intravenous; NA, not available; qw, every week; q2w, every two weeks; q4w, every 4 weeks; RCT, randomized controlled study; SC, subcutaneous; TCZ, tocilizumab; vs, versus; w, weeks. 
20 response ( $\geq 20 \%$ improvement in swollen joint count and in tender joint count plus $\geq 20 \%$ improvement in three of the following domains: Patient pain, patient global disease activity, physician global disease activity, physical function and acute-phase reactants ESR or CRP) between TCZ and placebo from the SATORI study. ${ }^{17}$

All patients included in these studies had an inadequate response to both synthetic and biologic DMARD therapy: 20\% had failed anti-TNF treatment prior to receiving TCZ. ${ }^{13-16}$

Patients' inclusion criteria were six or more swollen joints (66-joint count) and eight of more tender joints (68-joint counts) in the BREVACTA and MUSASHI studies, ${ }^{13,14,16}$ while the SUMMACTA study included patients with four or more swollen joints and four or more tender joints. ${ }^{15}$ Even though the criteria were stricter in the SUMMACTA study, the means of the swollen joint count (SJC), the tender joint count (TJC), and DAS28 (disease activity score) were equivalent in both the SUMMACTA and MUSASHI studies, ${ }^{15,16}$ suggesting greater variability in the SJC and TJC in the SUMMACTA study. ${ }^{15} \mathrm{CRP}$ and erythrocyte sedimentation rate (ESR) were also inclusion criteria that were equal between studies: CRP was $10 \mathrm{mg} / \mathrm{L}$ or higher and ESR was $28-30 \mathrm{~mm} / \mathrm{h}$ or higher. ${ }^{15,16}$

The three phase III studies permitted RA patients to continue their oral glucocorticoids $(\leq 10 \mathrm{mg}$ /day prednisolone or equivalent) and oral non-steroidal anti-inflammatory drugs during the course of the study. ${ }^{13-16}$ Nevertheless, the TCZ dosage and the use of concomitant DMARD was different in these three studies. The BREVACTA and SUMMACTA studies included patients receiving subcutaneous TCZ in combination with a stable dose of DMARD. ${ }^{13,14,16}$ In the SUMMACTA study patients received TCZ $162 \mathrm{mg}$ weekly, ${ }^{16}$ while patients in the BREVACTA study received TCZ $162 \mathrm{mg}$ q2w. ${ }^{13,14}$ In the BREVACTA study, 11\% of the patients increased TCZ to a weekly dose since they had less than 20\% improvement in their SJC and TJC between week 12 and $48 .{ }^{14}$ In the MUSASHI study, patients received TCZ $162 \mathrm{mg}$ q2w in monotherapy without any washout periods for synthetic DMARDs. ${ }^{16}$

Baseline characteristics of RA patients were not available in the BREVACTA study, but were available in the other studies. RA patients were comparable in terms of sex distribution, age, disease duration, disease activity (TJC, SJC, DAS28), physician's global assessment of disease activity, rheumatoid factor positivity, and CRP levels at baseline. ${ }^{15,16}$ Non-Japanese RA patients were heavier than Japanese: means of 74 versus (vs) $54 \mathrm{~kg} .{ }^{15,16}$ Japanese patients had lower pain scores and lower global assessment of disease activity than non-Japanese, ${ }^{15,16}$ possibly reflecting cultural differences between the enrolled patients. RA patients in the MUSASHI studies were more often anti-citrullinated protein antibody (ACPA) positive - 90\% vs 73\% - and used daily oral glucocorticoids more often $69 \%-59 \%$ vs $54 \%$. $^{15,16}$ Of interest, patients in the subcutaneous treatment arm were treated more frequently with glucocorticoids than the intravenous arm in the MUSASHI study. ${ }^{16}$

\section{TCZ pharmacokinetics}

(See Table 2). A previous phase II study in RA patients receiving intravenous TCZ $8 \mathrm{mg} / \mathrm{kg}$ q2w determined that a concentration of free $\mathrm{TCZ}$ above $1 \mu \mathrm{g} / \mathrm{mL}$ in the serum enables the binding of $95 \%$ of the soluble IL-6 receptor inhibiting IL-6 actions and doubling the IL-6 serum levels after 2 weeks. ${ }^{11}$ Serum concentration of free TCZ above $1 \mu \mathrm{g} /$ $\mathrm{mL}$ also normalized CRP in RA patients. ${ }^{11}$

In all the studies, RA patients receiving TCZ either $162 \mathrm{mg}$ weekly or q2w achieved a serum concentration of pre-dose TCZ (C trough) largely above $1 \mu \mathrm{g} / \mathrm{mL} .{ }^{12-16}$

Table 2 Pharmacokinetics of different subcutaneous tocilizumab dosages compared to intravenous tocilizumab in rheumatoid arthritis patients

\begin{tabular}{|c|c|c|c|c|c|c|}
\hline & TCZ dose & $\begin{array}{l}\text { C max } \\
\mu \mathrm{g} / \mathrm{mL} \\
\text { I dose }\end{array}$ & $\begin{array}{l}\mathrm{C} \max \mu \mathrm{g} / \mathrm{mL} \\
\text { during the } \\
\text { study }\end{array}$ & $\begin{array}{l}\text { Mean AUC } \\
\mu \mathrm{g} \mathrm{h} / \mathrm{mL}\end{array}$ & $\begin{array}{l}\text { Steady } \\
\text { state } \\
\text { weeks }\end{array}$ & $\begin{array}{l}\text { C trough } \\
\mu \mathrm{g} / \mathrm{mL}\end{array}$ \\
\hline \multirow[t]{3}{*}{ MATSURI'2 } & $81 \mathrm{mg} \mathrm{q} 2 \mathrm{w} \mathrm{SC}$ & 3.4 & NA & NA & NA & NA \\
\hline & 162 mg q2w SC & 11 & NA & NA & 15 & $6-9$ \\
\hline & 162 mg qw SC & II & NA & NA & 15 & $25-30$ at $15 w$ \\
\hline BREVACTA $^{13}$ & 162 mg q2w SC + DMARD & 10 & 17 at week 12 & 4,088 during weeks 12 to 14 & 20 & 7.4 at $24 w$ \\
\hline SUMMACTA ${ }^{15}$ & $\begin{array}{l}\text { I62 mg qw SC vs } 8 \text { mg/kg q4w } \\
\text { IV + DMARD }\end{array}$ & NA & $\begin{array}{l}53 \text { vs } 233 \\
\text { at week } 20\end{array}$ & $\begin{array}{l}30,168 \text { vs } 41,304 \text { during weeks } \\
20 \text { to } 24\end{array}$ & 12 & 42 vs 18 at 24 w \\
\hline MUSASHI ${ }^{16}$ & $\begin{array}{l}\text { I62 mg q2w SC vs } 8 \mathrm{mg} / \mathrm{kg} \mathrm{q} 4 \mathrm{w} \\
\text { IV monotherapy }\end{array}$ & NA & NA & NA & 12 & II vs 12 at $24 \mathrm{w}$ \\
\hline
\end{tabular}

Abbreviations: AUC, area under the curve; C max, maximal serum concentration of tocilizumab; $C$ trough, pre-dose tocilizumab serum concentration; DMARD, diseasemodifying antirheumatic drugs; IV, intravenous; NA, not available; qw, every week; q2w, every two weeks; q4w, every 4 weeks; SC, subcutaneous; TCZ, tocilizumab; vs, versus; w, weeks. 
Japanese patients receiving subcutaneous TCZ $162 \mathrm{mg}$ q2w and intravenous TCZ $8 \mathrm{mg} / \mathrm{kg}$ q $4 \mathrm{w}$ had similar pharmacokinetics. ${ }^{12,16}$ However, when subcutaneous TCZ $162 \mathrm{mg}$ was administered weekly in non-Japanese patients, the $\mathrm{C}$ trough level was two times higher than the $\mathrm{C}$ trough level of intravenous TCZ. ${ }^{15}$ On the other hand, RA patients receiving intravenous TCZ had higher maximal serum concentrations of free TCZ (C max) and a higher area under the curve. ${ }^{15}$

While the steady state of free TCZ concentration was achieved at week 12 in both the SUMMACTA and MUSASHI studies using two different subcutaneous TCZ dosages ${ }^{15,16}$ time to steady state seemed dependent on the TCZ dosage and the weight of RA patients. Administration of intravenous TCZ $8 \mathrm{mg} / \mathrm{kg} \mathrm{q} 2 \mathrm{w}$ led to a steady state at 6 weeks ${ }^{11}$ while it took 12 weeks when intravenous TCZ $8 \mathrm{mg} / \mathrm{kg}$ was administered q4w. ${ }^{15,16}$ While using the same subcutaneous dose of TCZ, the steady state was attained later in non-Japanese RA patients than in Japanese, ${ }^{13,14,16}$ possibly due to weight differences between patients. ${ }^{13,14}$ The time to steady state became equivalent between Japanese and non-Japanese RA patients when subcutaneous TCZ 162 mg was administered weekly in non-Japanese patients. ${ }^{15}$

Eighty to $91 \%$ of the RA patients receiving subcutaneous TCZ $162 \mathrm{mg} \mathrm{q} 2 \mathrm{w}$ in the MUSASHI study had serum free TCZ concentrations above $1 \mu \mathrm{g} / \mathrm{mL}$ after 4 weeks $^{16}$ inhibiting the IL- 6 actions and normalizing CRP. In the SUMMACTA study, CRP and ESR were slightly lower in RA patients receiving subcutaneous $162 \mathrm{mg}$ weekly than in patients receiving intravenous TCZ $8 \mathrm{mg} / \mathrm{kg} \mathrm{q} 4 \mathrm{w}$, possibly due to higher $\mathrm{C}$ trough with subcutaneous TCZ. ${ }^{15}$

\section{TCZ efficacy}

(See Table 3). Intravenous TCZ is effective in RA either in monotherapy or in combination with DMARD/MTX in both naïve patients and patients with an inadequate response to DMARD after 24 weeks. ${ }^{18,19}$ ACR20 response ranged from $56 \%-80 \%$, ACR50 response from 39\%-64\% and ACR70 response from $16 \%-44 \% .{ }^{19}$ Combination therapy of intravenous TCZ and MTX was not superior to TCZ monotherapy in patients with an inadequate response to DMARD. ${ }^{19,20}$

In the three phase III studies, subcutaneous TCZ used either in monotherapy or in combination with DMARD had similar ACR responses compared to the intravenous TCZ literature and were not statistically inferior to the intravenous TCZ arms. ${ }^{15,16}$ DAS28 remission (DAS28<2.6), clinical disease activity index (CDAI) and Boolean remission index were equal in both the subcutaneous and the intravenous administration of TCZ either in monotherapy or in combination with DMARD. ${ }^{15,16}$

ACR responses were lower in RA patients with antiTNF failure with ACR20-50-70 responses of 50\%, 28\%, and $11 \%$, respectively. ${ }^{19}$ In the ACT-SURE study (an open-label study close to clinical practice) RA patients with previous anti-TNF failure had lower DAS28 remission rates compared with anti-TNF naïve patients: $50 \%$ and $62 \%$, respectively. ${ }^{21}$ However, in the MUSASHI study, prior use of anti-TNF did not influence the efficacy of the subcutaneous TCZ treatment arm, whereas body mass index (BMI) in the fourth quartile (from 23.4 to $29.6 \mathrm{~kg} / \mathrm{m}^{2}$ ) decreased the ACR20-50-70 response rates significantly. ${ }^{16}$ Similarly, the ACR response rates of the heaviest category (weight $\geq 100 \mathrm{~kg}$ ) in both the subcutaneous and intravenous TCZ arms were lower in the SUMMACTA study. ${ }^{15}$

Table 3 Efficacy of subcutaneous tocilizumab in rheumatoid arthritis patients with inadequate response to DMARD

\begin{tabular}{|c|c|c|c|c|c|c|c|c|c|}
\hline & TCZ dose & Week & ACR20\% & ACR50-70\%* & DAS28 $<\mathbf{2 . 6} \%$ & CDAI $\leq \mathbf{2 . 8 \%}$ & Boolean \% & HAQ-DI $\geq 0.3 \%$ & $\begin{array}{l}\text { Insufficient } \\
\text { response \% }\end{array}$ \\
\hline \multirow[t]{3}{*}{ MATSURI'2 } & $81 \mathrm{mg} \mathrm{q} 2 \mathrm{w} \mathrm{SC}$ & 24 & 38 & $38-38$ & 50 & NA & NA & NA & NA \\
\hline & $162 \mathrm{mg} \mathrm{q} 2 \mathrm{w}$ SC & 24 & 83 & $83-50$ & 83 & NA & NA & NA & NA \\
\hline & $162 \mathrm{mg}$ qw SC & 24 & 92 & $92-67$ & 100 & NA & NA & NA & NA \\
\hline \multirow[t]{2}{*}{ BREVACTA $^{13,14}$} & 162 mg q2w SC & 24 & 61 & $40-20$ & 32 & NA & NA & 58 & 0.9 \\
\hline & + DMARD & 48 & 62 & $45-26$ & 45 & NA & NA & 62 & \\
\hline SUMMACTA ${ }^{15}$ & $\begin{array}{l}162 \mathrm{mg} \text { qw SC } \\
+ \text { DMARD }\end{array}$ & 24 & 68 & $46-24$ & 37 & 14 & II & 65 & 1.7 \\
\hline MUSASHI' ${ }^{16}$ & $\begin{array}{l}162 \mathrm{mg} \text { q2w SC } \\
\text { monotherapy }\end{array}$ & 24 & 79 & $64-37$ & 50 & 16 & 16 & 57 & 1.7 \\
\hline SUMMACTA and & $8 \mathrm{mg} / \mathrm{kg}$ IV q4w & 24 & 70 & $47-27$ & 38 & 15 & 11 & 67 & 1.3 \\
\hline MUSASHI studies 15,16 & $8 \mathrm{mg} / \mathrm{kg}$ IV q4w & 24 & 89 & $67-41$ & 62 & 23 & 16 & 68 & 0.6 \\
\hline
\end{tabular}

Note: *The numbers listed first in this column refer to the percentage of the patients achieving the ACR50 response, and the numbers listed second in this column refer to the percentage of patients achieving the ACR70 response. By definition, all the patients achieving ACR70 achieve ACR50.

Abbreviations: ACR, American College of Rheumatology response rate; CDAl, clinical disease activity index; DAS, disease activity score; DMARD, disease-modifying antirheumatic drugs; HAQ-DI, health assessment questionnaire disability index; IV, intravenous; NA, not available; qw, every week; q2w, every two weeks; q4w, every four weeks; SC, subcutaneous; TCZ, tocilizumab. 
ACR20-50-70 responses were significantly lower when TCZ was administered at half dose $-4 \mathrm{mg} / \mathrm{kg} \mathrm{q} 4 \mathrm{w}$ in combination with DMARD. ${ }^{19}$ Although there was no difference in efficacy between both TCZ intravenous dosages $-4 \mathrm{mg} / \mathrm{kg}$ vs $8 \mathrm{mg} / \mathrm{kg}$ in an open-label clinical practice study, $58 \%$ of the patients had dose escalation from $4-8 \mathrm{mg} / \mathrm{kg}$ during the course of the study. ${ }^{22}$ The efficacy of subcutaneous TCZ $162 \mathrm{mg}$ q2w in combination with DMARD seemed equal to TCZ $162 \mathrm{mg}$ weekly, ${ }^{14,15}$ although $18 \%$ of the patients withdrew from BREVACTA and received escape therapy with weekly subcutaneous TCZ. ${ }^{14}$ Still, $80 \%$ of non-Japanese RA patients treated with TCZ $162 \mathrm{mg} \mathrm{q} 2 \mathrm{w}$ in combination with DMARD achieved similar efficacy compared with TCZ administered weekly. ${ }^{14}$

Sustained efficacy of intravenous TCZ was demonstrated in the STREAM study when $66 \%$ of the patients were still receiving intravenous TCZ $8 \mathrm{mg} / \mathrm{kg} \mathrm{q} 4 \mathrm{w}$ monotherapy after 5 years. ${ }^{23}$ In the STREAM study, TCZ was only stopped in $0.7 \%$ of the patients due to an insufficient response, although $5.6 \%$ withdrew due to personal reasons. ${ }^{23}$ Sustained efficacy was also indirectly demonstrated in the DREAM study when at baseline 187 RA patients with previous inadequate response to DMARD had low disease activity (DAS28 $\leq 3.2)$ after receiving a median of 4 years of intravenous TCZ monotherapy. ${ }^{24}$ Intravenous TCZ had sustained efficacy in RA patients with prior DMARD and anti-TNF treatment failures (93\%) since TCZ drug survival was $64 \%$ at 48 weeks and only $11 \%$ of the patients discontinued TCZ due to lack of efficacy in the Danish DANBIO registry..$^{25}$

Long-term efficacy of combining synthetic DMARD with subcutaneous TCZ was maintained over 48 weeks since less than $1 \%$ withdrew from the BREVACTA study. ${ }^{14}$ In the SUMMACTA and MUSASHI studies, only 1.7\% had insufficient therapeutic response with subcutaneous $\mathrm{TCZ}$, not different from the intravenous TCZ treatment arms at 24 weeks. ${ }^{15,16}$

Intravenous TCZ either in monotherapy or in combination with MTX delayed radiographic progression at 52 weeks $^{18}$ independently of its effect on disease activity, similar to anti-TNF treatment. ${ }^{26}$ In the BREVACTA study, there was almost no radiographic progression of structural joint damage from baseline and this remained unchanged from week 24-48, changes using the modified total Sharp score were $0.6 \pm 2.7$ at 24 weeks and $0.6 \pm 3.3$ at 48 weeks. ${ }^{14}$

\section{TCZ safety}

(See Table 4). TCZ had sustained efficacy and high retention rates suggesting acceptable safety. ${ }^{19}$ Cumulative safety data from RA trials yielded a rate of adverse events (AE) of 278 per 100 person-years (PY) and a rate of serious adverse events (SAE) of 14/100 PY. ${ }^{27}$ In the ACT-SURE and ACT-RAY studies, close to clinical practice, the rates of $\mathrm{AE}$ and SAE were significantly higher, 593 and 491/100 PY, and 20 and 21/100 PY, respectively. ${ }^{20,21}$ In the ACT-STAR and STREAM studies, the overall rates of SAE were highest with 28/100 PY in both studies. ${ }^{22,23}$ While the most common SAE were infections, ${ }^{20,21}$ it was joint surgery in the long-term STREAM study, occurring in $14 \%$ of RA patients. ${ }^{23}$ Previous use of anti-TNF ${ }^{21,22}$ and concomitant use of synthetic DMARD ${ }^{20,22}$ with intravenous TCZ did not increase SAE.

The rates of SAE in RA patients receiving subcutaneous TCZ were similar to the rates in intravenous TCZ RA trials, ${ }^{27}$ but were lower when compared with studies close to clinical practice. ${ }^{20-22}$ Rates of SAE were not different if patients received either $162 \mathrm{mg}$ weekly or $\mathrm{q} 2 \mathrm{w}$ and if patients received intravenous TCZ. ${ }^{14,15}$ The most common SAE in RA patients receiving subcutaneous $\mathrm{TCZ}$ were infections, ${ }^{14,15}$ similar to studies of equal duration.

Rates of severe infections (SI) ranged from 4.2-11.2 infections per $100 \mathrm{PY}{ }^{20-23}$ The most common infections were localized in the upper and lower airways. ${ }^{20,22,23}$ Cellulitis and herpes zoster infection came second respectively in the ACTSTAR and STREAM studies. ${ }^{22,23}$ In the STREAM study, SI such as pneumonia, herpes zoster infection, acute bronchitis, and pyelonephritis were found in $6.3 \%, 4.9 \%, 1.4 \%$, and $1.4 \%$, respectively, of the observed SAE with corresponding rates of $1.5,1.1,0.8,0.5$ events per $100 \mathrm{PY}^{23}$ Combination of intravenous TCZ $8 \mathrm{mg} / \mathrm{kg}$ with DMARD increased the risk of infections by $30 \%$ compared with controls receiving TCZ and placebo; however there was no difference between the two intravenous TCZ dosages -4 and $8 \mathrm{mg} / \mathrm{kg} \mathrm{q} 4 \mathrm{w} \cdot{ }^{28}$ The incidence of infections and SI seemed lower in RA patients with less than 2 years of disease duration. ${ }^{19}$

Rates of SI in RA patients receiving subcutaneous TCZ seemed lower - 3.1 and 3.8 infections per 100 PY..$^{14,15}$ Although infections and SI frequency and rates were similar in both treatment arms, two patients had bacterial arthritis ${ }^{15}$ and two patients had herpes zoster infection ${ }^{16}$ in the intravenous TCZ arms, compared to none in the subcutaneous TCZ treatment arms. No cases of tuberculosis were reported when using subcutaneous $\mathrm{TCZ}^{14-16}$ similar to intravenous TCZ. ${ }^{28}$

Mean neutrophil counts decreased during intravenous TCZ treatment in RA patients, but usually remained inside the normal range. ${ }^{23}$ Grade 2 and 3 neutropenia (neutrophil counts between 1.0 to $1.5 \times 10^{9} / \mathrm{L}$ and between 0.5 to $1.0 \times 10^{9} / \mathrm{L}$ ) occurred in 


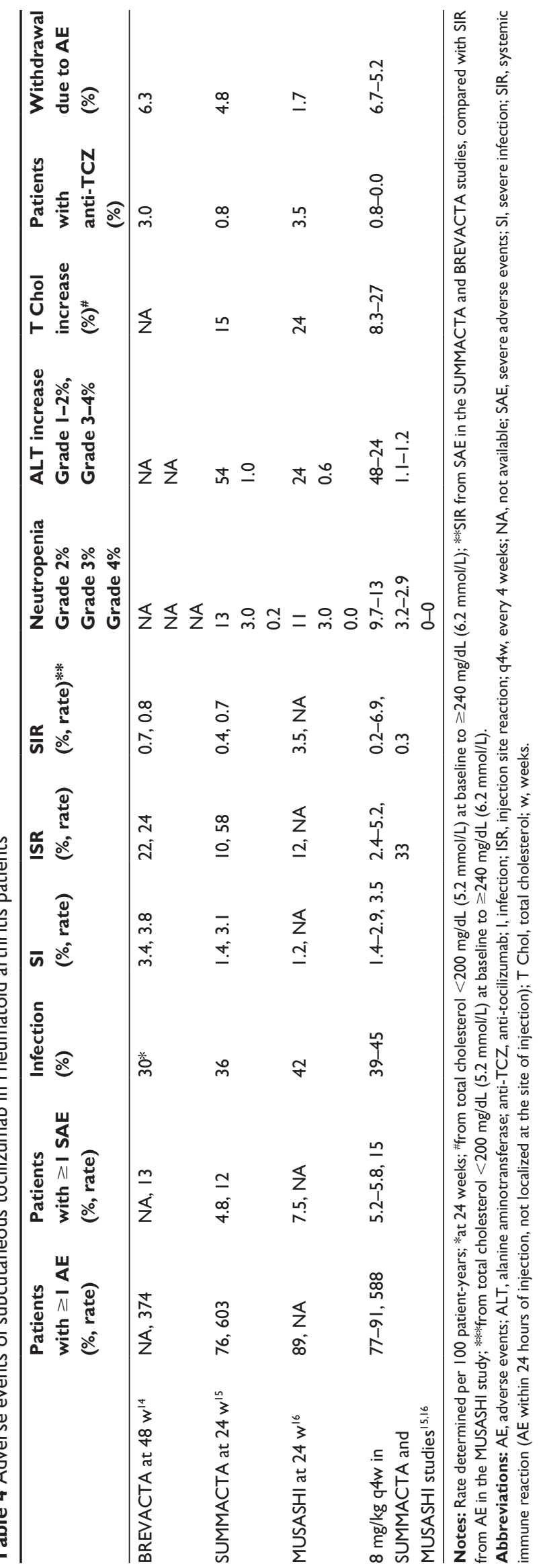

$7.0 \%-11 \%$ and $2.2 \%-6.1 \%$, respectively. ${ }^{22,23}$ No patients had grade 4 neutropenia (neutrophil count $<0.5 \times 10^{9} / \mathrm{L}$ ). ${ }^{22,23}$ In the ACT-STAR study, a proportion of RA patients with grade 2 and 3 neutropenia seemed higher in the treatment arm combining intravenous TCZ $8 \mathrm{mg} / \mathrm{kg}$ and DMARD compared to the TCZ monotherapy.2. TCZ seemed to cause neutropenia since the risk of grade 3 neutropenia was negligible in MTX monotherapy compared to intravenous TCZ monotherapy, $0.4 \%$ vs $3.1 \%$ respectively. ${ }^{29}$ Neutropenia was usually transient independently of its grade and returned to normal after discontinuation of TCZ. ${ }^{19}$

In RA patients receiving subcutaneous $\mathrm{TCZ}$, the risk of neutropenia seemed similar to that of the intravenous TCZ arms. ${ }^{15,16}$ Of interest, one patient in the SUMMACTA study had grade 4 neutropenia. ${ }^{15}$ Neutropenia was responsible for neither febrile neutropenia nor infections in RA patients receiving $\mathrm{TCZ},{ }^{28}$ independent of its administration route. ${ }^{15}$

Alanine aminotransferase (ALT) increased during TCZ from 19-26 UI/L at 24 weeks. ${ }^{30}$ In the long-term study STREAM, ALT increased slightly, but remained within normal range at 5 years. ${ }^{23}$ ALT elevation was mostly transient occurring only once in $49 \%$ and more than once in $7.8 \%$ of the patients receiving intravenous TCZ $8 \mathrm{mg} / \mathrm{kg}$ in combination with DMARD. ${ }^{20} \mathrm{ALT}$ elevation was less frequent in RA patients receiving intravenous TCZ monotherapy, $1.2 \%$ compared with $28 \%$ receiving combination. ${ }^{20}$ Because of its transient character, TCZ discontinuation secondary to grade 1 and 2 elevation of ALT (up to five times the upper normal level) was infrequent, around $2 \% .{ }^{9}$ No liver injury and hepatitis secondary to TCZ have been reported, except for one case of histologic hepatocellular necrosis that did not lead to its discontinuation. ${ }^{19}$

The frequency of ALT elevation in patients receiving subcutaneous TCZ was similar to intravenous TCZ. The combination of subcutaneous TCZ and DMARD seemed to increase the risk of ALT elevation compared with monotherapy. ${ }^{15,16}$ Only one patient $(0.2 \%)$ had sustained elevation of ALT and five patients $(0.8 \%)$ discontinued TCZ due to ALT elevation in the SUMMACTA study. ${ }^{15}$

Total cholesterol levels increased in the first 6 weeks of TCZ treatment and stabilized afterwards. ${ }^{19}$ Total cholesterol increased from $93 \mathrm{mg} / \mathrm{dL}$ to $103 \mathrm{mg} / \mathrm{dL}$ at 24 weeks in the ACT-RAY study, ${ }^{20}$ whereas it increased from 185 at baseline to 220 at 12 months and $214 \mathrm{mg} / \mathrm{dL}$ at 60 months in the long-term STREAM study. ${ }^{23}$ Use of lipid-lowering treatment with statins was different between studies, at baseline 1.4\% of Japanese patients used statins in the STREAM study ${ }^{23}$ whereas $21 \%$ of non-Japanese patients used statins at baseline 
in the ACT-STAR study. ${ }^{22}$ Nevertheless, during the course of TCZ, $35 \%$ and $32 \%$ of the patients in both studies used statins, although the studies' duration was unequal (5 years vs 24 weeks). ${ }^{22,23}$ Dyslipidemia induced by TCZ did not appear to increase the risk of serious cardiovascular disease. ${ }^{19}$

Fifteen and $24 \%$ of RA patients receiving subcutaneous TCZ increased their total cholesterol levels from less than $200 \mathrm{mg} / \mathrm{dL}$ to over $240 \mathrm{mg} / \mathrm{dL}$ respectively in the SUMMACTA and MUSASHI studies. ${ }^{15,16}$ Total cholesterol levels seemed to increase less in non-Japanese patients, however, only $47 \%$ of the non-Japanese patients had total cholesterol levels less than $200 \mathrm{mg} / \mathrm{dL}$ at baseline ${ }^{15}$ compared with $79 \%$ of the Japanese patients. ${ }^{16}$ Another possible explanation could be that non-Japanese patients were more often treated with statins at baseline. ${ }^{15}$ The authors of the SUMMACTA study mentioned that clinically relevant shifts in low-density lipoprotein cholesterol, high-density lipoprotein cholesterol, and triglyceride levels were similar between the subcutaneous and intravenous treatment arms. ${ }^{15}$

Rates of intravenous TCZ withdrawal due to AE or SAE ranged from $2.9 \%-8.8 \%$ at 24 weeks, ${ }^{20-22}$ mostly due to infections. ${ }^{21}$ Combination of TCZ and synthetic DMARD did not seem to increase the risk of withdrawal due to $\mathrm{AE}$ and SAE. ${ }^{22}$ In the long-term STREAM study, 22\% of the patients withdrew from TCZ due to SAE, however, TCZ was frequently interrupted - 163 interruptions for 8 weeks or more in 143 RA patients during 5 years. ${ }^{23}$

The rates of subcutaneous TCZ withdrawal were similar to intravenous, ranging from $1.7 \%-6.3 \% .^{14-16}$ Contrary to intravenous, subcutaneous TCZ monotherapy seemed to have lower withdrawal rates due to AE. ${ }^{14-16}$

Anti-TCZ antibodies were not more frequently detected in patients receiving subcutaneous TCZ compared with intravenous TCZ when combined with DMARD. ${ }^{15}$ However, anti-TCZ antibodies were more frequent in patients receiving subcutaneous TCZ monotherapy. ${ }^{16}$ Due to the low number of patients with anti-TCZ antibodies and the short duration of the studies, the consequences of anti-TCZ antibodies - in terms of AE and loss of efficacy - remain unknown.

Ten deaths $(0.3 \%)$ were recorded during the ACT-SURE, ACT-STAR, and ACT-RAY studies ${ }^{20-22}$ while the number of deaths was not reported during the long-term STREAM study. ${ }^{23}$ Four deaths were due to sepsis. ${ }^{20-22}$

Six deaths were recorded in the BREVACTA study ${ }^{14}$ while none were recorded in the other two studies ${ }^{15,16}$ corresponding to $0.5 \%$ of all the RA patients treated with subcutaneous TCZ. The causes of deaths were not reported in the BREVACTA study. ${ }^{14}$

\section{Summary: from the physician's to the patients' perspective}

Subcutaneous TCZ seems to be as effective as intravenous TCZ in treating RA patients either in monotherapy or in combination with DMARD. Subcutaneous TCZ offers patients the additional option of self-administration, which is important for patients with chronic disease who usually prefer to be treated at home. Reducing the number of hospital visits due to intravenous treatment could decrease societal and medical costs.

While EULAR recommendations in RA stated that biologic DMARD should be commenced with MTX, they also acknowledged that TCZ is the only biologic DMARD that demonstrated superior effects compared to MTX and which has some evidence supporting its use in monotherapy. ${ }^{6}$ Recently, intravenous TCZ monotherapy was found more effective than adalimumab in RA patients for whom MTX was deemed inappropriate ${ }^{30}$ and was more effective than abatacept after anti-TNF and rituximab failure. ${ }^{31}$ Even though physician surveys indicate that a DMARD was prescribed with a biologic agent in $80 \%-90 \%$ of the RA patients, ${ }^{32}$ biologic monotherapy is commonly used in clinical practice - at least $30 \%$ and up to $54 \%$. $^{29,33}$ Subcutaneous TCZ could conciliate both treatment efficacy and patients' personal preferences.

Safety of subcutaneous TCZ seemed similar to intravenous TCZ in the short-term. No infections secondary to neutropenia, episodes of liver failure or increased risk of cardiovascular diseases were recorded in studies evaluating subcutaneous TCZ. The safety profile of intravenous TCZ compared to other biologic DMARD was similar in terms of SAE, SI, lymphoma, and congestive heart failure. ${ }^{34}$ The risks of infections ${ }^{28}$ and ALT elevation ${ }^{20}$ seemed to be increased in RA patients receiving intravenous TCZ ( $8 \mathrm{mg} / \mathrm{kg} \mathrm{q} 4 \mathrm{w})$ in combination with DMARD compared with patients receiving TCZ monotherapy. However, higher $\mathrm{C}$ max concentrations in RA patients receiving intravenous $\mathrm{TCZ}$ and higher $\mathrm{C}$ trough concentrations in patients receiving subcutaneous TCZ could lead to differences in AE and possibly in efficacy. Subcutaneous TCZ is therefore well tolerated, especially when administered in monotherapy although its subcutaneous administration could theoretically expose patients to auto-immunogenicity. ${ }^{35}$

Since RA patients were observed during 24 and 48 weeks, long-term effects and safety of subcutaneous TCZ have not yet been assessed. Still, long-term efficacy and safety of intravenous TCZ seemed good when measured in retention 
rate. ${ }^{19,23}$ Retention rate in RA patients who were nonresponders to anti-TNF was higher with biologic DMARD other than anti-TNF, ${ }^{36}$ and between TCZ and infliximab ${ }^{37}$ in two small cohort studies.

Monotherapy with intravenous TCZ has prolonged efficacy after its discontinuation since $13 \%$ of RA patients, who had received TCZ for a median of 4 years, had low disease activity 52 weeks after discontinuation. ${ }^{24}$ Re-treatment with TCZ was well tolerated and effective in RA patients who experienced loss of efficacy after TCZ discontinuation. ${ }^{38}$

Although the subcutaneous dosages of TCZ $162 \mathrm{mg}$ every week and q2w in RA patients with low body weight $(<60 \mathrm{~kg})$ worked well, dosage and intervals of subcutaneous TCZ administration could be adjusted during the course of treatment.

Simple and important issues relevant to patients' preference and adherence, such as the place of TCZ in RA treatment algorithms as a first-line or second-line treatment, its dosage and treatment intervals especially during long-term remission, have not yet been assessed since these issues are often not prioritized.

Patients want effective, easy-to-administer therapy with sustained prolonged efficacy without the need of polypharmacy and with minimal to no side effects. Subcutaneous TCZ in RA patients in monotherapy promises to live up to patients' expectations.

\section{Disclosure}

The author reports no conflicts of interest in this work.

\section{References}

1. Davis JM III, Matteson EL. American College of Rheumatology, European League Against Rheumatism. My treatment approach to rheumatoid arthritis. Mayo Clin Proc. 2012;87(7):659-673.

2. Allaire S, Wolfe F, Niu J, Lavalley MP. Contemporary prevalence and incidence of work disability associated with rheumatoid arthritis in the US. Arthritis Rheum. 2008;59(4):474-480.

3. Gabriel SE, Crowson CS, Kremers HM, et al. Survival in rheumatoid arthritis: a population-based analysis of trends over 40 years. Arthritis Rheum. 2003;48(1):54-58.

4. Aletaha D, Neogi T, Silman AJ, el al. 2010 Rheumatoid arthritis classification criteria: an American College of Rheumatology/European League Against Rheumatism collaborative initiative. Arthritis Rheum. 2010;62(9):2569-2581.

5. Smolen JS, Aletaha D, Bijlsma JW, et al. Treating rheumatoid arthritis to target: recommendations of an international task force. Ann Rheum Dis. 2010;69(4):631-637.

6. Smolen JS, Landewé R, Breedveld FC, et al. EULAR recommendations for the management of rheumatoid arthritis with synthetic and biological disease-modifying antirheumatic drugs: 2013 update. Ann Rheum Dis. 2014;73(3):492-509.

7. Scheller J, Chalaris A, Schmidt-Arras D, Rose-John S. The pro- and anti-inflammatory properties of the cytokine interleukine-6. Biochim Biophys Acta. 2011;1813(5):878-888.
8. Ash Z, Emery P. The role of tocilizumab in the management of rheumatoid arthritis. Expert Opin Biol Ther. 2012;12(9):1277-1289.

9. Alten R, Maleitzke T. Tocilizumab: a novel humanized anti-interleukin 6 (IL-6) receptor antibody for the treatment of patients with non-RA systemic, inflammatory rheumatic disease. Ann Med. 2013;45(4):357-363.

10. Schiff M. Subcutaneous abatacept for the treatment of rheumatoid arthritis. Rheumatology (Oxford). 2013;52(6):986-997.

11. Nishimoto N, Terao K, Mima T, Nakahara H, Takagi N, Kakehi T. Mechanisms and pathologic significances in increase in serum interleukine-6 (IL-6) and soluble IL-6 receptor after administration of an anti-IL-6 receptor antibody, tocilizumab, in patients with rheumatoid arthritis and Castleman disease. Blood. 2008;112(10):3959-3964.

12. Ohta $\mathrm{S}$, Tsuru T, Terao K, et al. Mechanism-based approach using a biomarker response to evaluate tocilizumab subcutaneous injection in patients with rheumatoid arthritis with an inadequate response to synthetic DMARDs (MATSURI study). J Clin Pharmacol. 2014; 54(1):109-119.

13. roche-trials.com [homepage on the internet]. F. Hoffman-La Roche Ltd. Clinical trial result information: protocol number NA25220. ClinicalTrials.gov identifier NCT 01232569. Available from http:// www.roche-trials.com/studyResultGet.action?studyResultNumber $=\mathrm{N}$ A25220. Accessed February 1, 2014.

14. Kivitz A, Olech E, Borofsky MA, et al. The safety and efficacy of tocilizumab subcutaneous in combination with traditional DMARDS in patients with moderate to severe rheumatoid arthritis up to 48 weeks (BREVACTA). Arthritis Rheum. 2013;65:s604-s605.

15. Burmester GR, Rubbert-Roth A, Cantagrel A, et al. A randomised, double-blind, parallel-group study of the safety and efficacy of subcutaneous tocilizumab versus intravenous tocilizumab in combination with traditional disease-modifying antirheumatic drugs in patients with moderate to severe rheumatoid arthritis (SUMMACTA study). Ann Rheum Dis. 2014;73(1):69-74.

16. Ogata A, Tanimura K, Sugimoto T, et al. Phase III study of the efficacy and safety of subcutaneous versus intravenous tocilizumab monotherapy in patients with rheumatoid arthritis. Arthritis Care Res (Hoboken). 2014;66(3):344-354.

17. Nishimoto N, Miyasaka N, Yamammoto K, et al. Study of active controlled tocilizumab monotherapy for rheumatoid arthritis patients with an inadequate response to methotrexate (SATORI): significant reduction in disease activity and serum vascular endothelial growth factor by IL-6 receptor inhibition therapy. Mod Rheumatol. 2009;19(1):12-19.

18. Al-Shakarchi I, Gullick NJ, Scott DL. Current perspectives on tocilizumab for the treatment of rheumatoid arthritis: a review. Patient Prefer Adherence. 2013;7:653-666.

19. Schoels MM, van der Heijde D, Breedveld FC, et al. Blocking the effects of interleukin-6 in rheumatoid arthritis and other inflammatory rheumatic diseases: systematic literature review and meta-analysis informing a consensus statement. Ann Rheum Dis. 2013;72(4):583-589.

20. Dougados M, Kissel K, Sheeran T, et al. Adding tocilizumab or switching to tocilizumab monotherapy in methotrexate inadequate responders: 24-week symptomatic and structural results of a 2-year randomised controlled strategy trial in rheumatoid arthritis (ACT-RAY). Ann Rheum Dis. 2013;72(1):43-50.

21. Byberk VP, Östör AJK, Alvaro-Gracia J, et al. Tocilizumab in patients with active rheumatoid arthritis and inadequate responses to DMARDs and/or TNF inhibitors: a large, open-label study close to clinical practice. Ann Rheum Dis. 2012;71(12):1950-1954.

22. Weinblatt ME, Kremer J, Cush J, et al. Tocilizumab monotherapy or in combination with non-biologic disease-modifying antirheumatic drugs: twenty-four-week results of an open-label, clinical practice study. Arthritis Care Res (Hoboken). 2013;65(3):362-371.

23. Nishimoto N, Miyasaka N, Yamomoto K, Kawai S, Takeuchi T, Azuma J. Long-term safety and efficacy of tocilizumab, an anti-IL-6 receptor monoclonal antibody, in monotherapy, in patients with rheumatoid arthritis (the STREAM study): evidence of safety and efficacy in a 5-year extension study. Ann Rheum Dis. 2009;68(10): $1580-1584$. 
24. Nishimoto N, Amano K, Hirabayashi Y, et al. Drug free remission/low disease activity after cessation of tocilizumab (Actemra) monotherapy (DREAM) study. Mod Rheumatol. 2014;24(1):17-25.

25. Leffers HC, Østergaard M, Glintborg B, et al. Efficacy of abatacept and tocilizumab in patients with rheumatoid arthritis treated in clinical practice: results from the nationwide Danish DANBIO registry. Ann Rheum Dis. 2011;70(7):1216-1222.

26. Smolen JS, Martinez Avila JC, Aletaha D. Tocilizumab inhibits progression of joint damage in rheumatoid arthritis irrespective of its antiinflammatory effects: disassociation of the link between inflammation and destruction. Ann Rheum Dis. 2012;71(5):687-693.

27. Schiff MH, Kremer JM, Jahres A, et al. Integrated safety in tocilizumab clinical trials. Arthritis Res Ther. 2011;13(5):R141.

28. Campbell L, Chen C, Bhagat SS, Parker RA, Ostor AJ. Risk of adverse events including serious infections in rheumatoid arthritis patients treated with tocilizumab: a systematic literature review and metaanalysis of randomized controlled trials. Rheumatology (Oxford). 2011;50(3):552-562

29. Gómez-Reino J. Biologics monotherapy as initial treatment in patients with early rheumatoid arthritis. Rheumatology (Oxford). 2012;51 Suppl 5:31-37.

30. Gabay C, Emery P, van Vollenhoven R, et al. Tocilizumab monotherapy versus adalimumab monotherapy for treatment of rheumatoid arthritis (ADACTA): a randomised double-blind, controlled phase 4 trial. Lancet. 2013;381(9877):1541-1550.
31. Das S, Vital EM, Horton S, et al. Abatacept or tocilizumab after rituximab arthritis? An exploratory study suggests non-response to rituximab is associated with persistently high IL-6 and better clinical response to IL-6 blocking therapy. Ann Rheum Dis. 2014;73(5):909-912.

32. Choquette D, Arundine M, Thomas O. Large discrepancy between expected and observed ratios of biologic treated rheumatoid arthritis patients also compliant on DMARDS. Ann Rheum Dis. 2011;70:197.

33. Emery P, Sebba A, Huizinga TW. Biologic and oral disease-modifying antirheumatic drug monotherapy in rheumatoid arthritis. Ann Rheum Dis. 2013;72(12):1897-1904.

34. Singh JA, Wells GA, Christensen R, et al. Adverse effects of biologics: a network meta-analysis and Cochrane overview (review). Cochrane Database Syst Rev. 2011;16(2):CD008794.

35. Schellekens H. The immunogenicity of therapeutic proteins. Discov Med. 2010;9(49):560-564.

36. Favalli EG, Biggioggero M, Marchesoni A, Meroni PL. Survival on treatment with second-line biologic therapy: a cohort study comparing cycling and swap strategies. Rheumatology (Oxford). Epub 2014 Apr 12.

37. Golmia RP, Scheinberg MA. Retention rates of infliximab and tocilizumab during a 3-year period in a Brazilian hospital. Einstein (Sao Paulo). 2013;11(4):492-494.

38. Nishimoto N, Amano K, Hirabayashi Y, et al. Retreatment efficacy and safety of tocilizumab in patients with rheumatoid arthritis in recurrence (RESTORE) study. Mod Rheumatol. 2014;24(1):26-32.
Patient Preference and Adherence

\section{Publish your work in this journal}

Patient Preference and Adherence is an international, peer-reviewed, open access journal that focuses on the growing importance of patient preference and adherence throughout the therapeutic continuum. Patient satisfaction, acceptability, quality of life, compliance, persistence and their role in developing new therapeutic modalities and compounds to optimize

\section{Dovepress}

clinical outcomes for existing disease states are major areas of interest for the journal. This journal has been accepted for indexing on PubMed Central. The manuscript management system is completely online and includes a very quick and fair peer-review system, which is all easy to use. Visit http://www. dovepress.com/testimonials.php to read real quotes from published authors. 